\title{
A rare cause of non-atherosclerotic myocardial infarction: Rheumatoid arthritis
}

\author{
Non-aterosklerotik miyokart infarktüsünün nadir bir nedeni: Romatoid artrit
}

Ziya Şimşek ${ }^{1}$, M. Hakan Taş', Emrah İpek²

\section{Dear Editor,}

Cardiovascular involvement is common in rheumatoid arthritis [1]. Pericarditis, cardiomyopathy, myocarditis, cardiac amyloidosis, coronary vasculitis, arrhythmias, valvular heart disease and congestive heart failure due to ischemia can be seen in addition to the classical extra-articular involvement [2]. Patients with rheumatoid arthritis are under risk of accelerated atherosclerosis and myocardial infarction due to increased inflammation. Endothelial dysfunction is an important mechanism for thrombosis in these patients [3]. Pro-inflammatory cytokines (interleukin-1 beta and tumor necrosis factor alpha, C-reactive protein), activated coagulation factors (tissue factor, von Willebrand factor and plasminogen activator inhibitor-1), increased activity of cell adhesion molecules (selectins, vascular adhesion molecule-1, intercellular adhesion molecule-1) and matrix metalloproteinases are responsible for this endothelial dysfunction leading thrombosis [3]. The risk is especially higher in patients who have used or are using glucocorticoids [4]. In patients with Cushing's syndrome due to chronic steroid use, accumulation of cardio-metabolic risk factors like visceral obesity, hypertension, hyperglycemia and hyperlipidemia results in acceleration of cardiovascular disease [4]. Additionally, a hypercoagulability state was also detected in patients with endogenous Cushing's syndrome [5]. Herein we present a patient with rheumatoid arthritis who had extensive coronary thrombosis and was given steroid therapy for a long time. J Clin Exp Invest 2013; 4 (4): 568-569

A 34-year-old female patient who was previously evaluated in another center with the complaints of sudden onset chest pain and vertigo, was admitted to our clinic with the diagnosis of acute right ven- tricular and inferior wall myocardial infarction. Electrocardiogram revealed first degree atrioventricular block and ST-segment elevation in inferior and right precordial leads. She did not have history of cardiovascular disease or any risk factor. She was on 20 $\mathrm{mg}$ oral methylprednisolone treatment daily for eight years due to rheumatoid arthritis. Cushing's syndrome developed because of the steroid therapy. The transthorasic echocardiography revealed apical and inferior wall hypokinesia with concomitant right ventricular lateral wall akinesia. After the first assessment, she was transferred to the coronary angiography unit. In coronary angiography, the right coronary artery was totally occluded proximally, the circumflex artery was filled by thrombus up to its second obtuse marginal branch and the left anterior descending artery had a dense thrombus after its second diagonal branch [Fig 1 and 2].

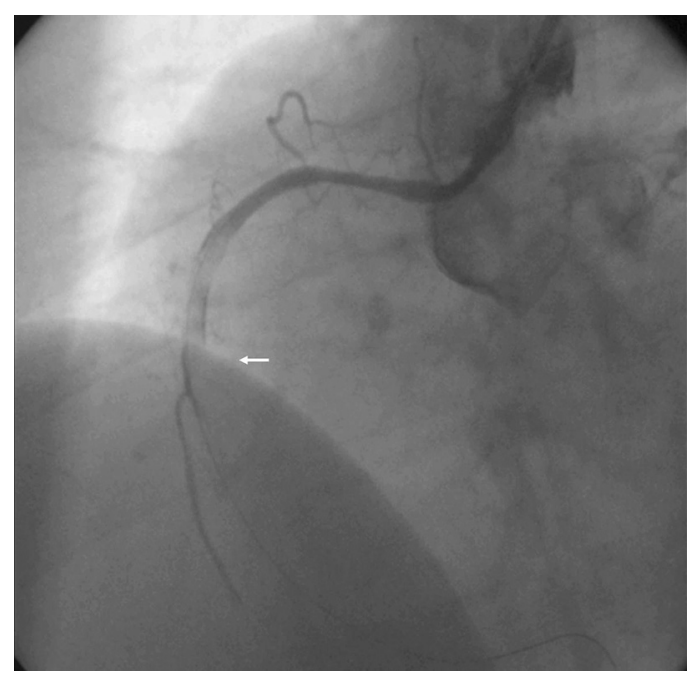

Figure 1. Total thrombotic lesion in right coronary artery

${ }^{1}$ Department of Cardiology, Faculty of Medicine, Ataturk University, Erzurum, Turkey

${ }^{2}$ Department of Cardiology, Erzurum Education and Research Hospital, Erzurum, Turkey

Correspondence: Ziya Şimşek,

Department of Cardiology, Faculty of Medicine, Ataturk University, Erzurum, Turkey Email: ziyamposta@hotmail.com

Received: 12.04.2013, Accepted: 23.07.2013

Copyright (C) JCEI / Journal of Clinical and Experimental Investigations 2013, All rights reserved 


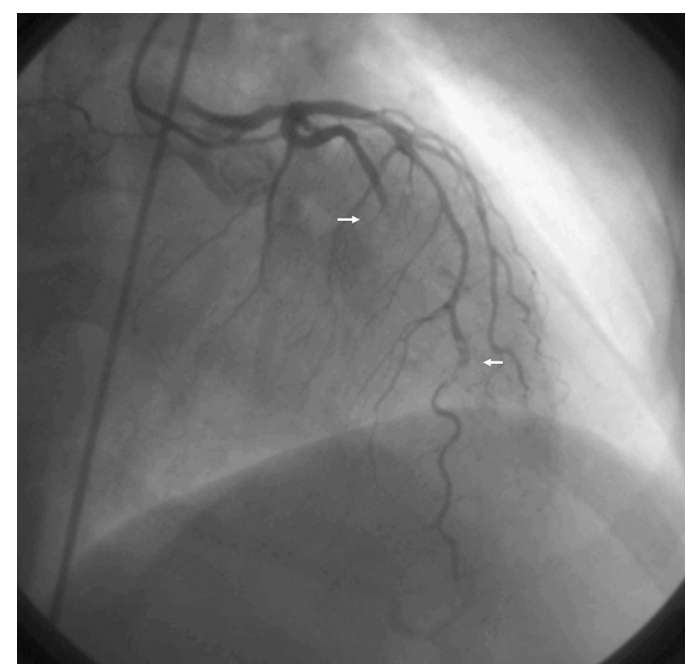

Figure 2. Diffuse thrombotic lesions in the left system

Inferior wall akinesia and apical hypokinesia were detected in ventriculography. Left ventricular systolic and end-diastolic pressures were 90 and $10 \mathrm{mmHg}$, respectively. Percutaneous transluminal coronary angioplasty was performed to the right coronary artery; however, any distal flow could not be restored. Thrombolytic therapy with tissue plas- minogen activator was started at the 8th hour of the infarction since the percutaneous intervention was failed. However, the patient did not benefit from the thrombolytic therapy and died due to cardiogenic shock at the 12th hour of the infarction.

\section{REFERENCES}

1. Liao KP, Solomon DH. Traditional cardiovascular risk factors, inflammation and cardiovascular risk in rheumatoid arthritis. Rheumatology (Oxford) 2013;52:4552.

2. Koivuniemi R, Paimela L, Suomalainen R, et al. Cardiovascular diseases in patients with rheumatoid arthritis. Scand J Rheumatol 2013;42:131-135.

3. Hürlimann D, Enseleit F, Ruschitzka F. Rheumatoid arthritis, inflammation, and atherosclerosis. Herz 2004;29:760-768.

4. Aviña-Zubieta JA, Abrahamowicz M, De Vera MA, et al. Immediate and past cumulative effects of oral glucocorticoids on the risk of acute myocardial infarction in rheumatoid arthritis: a population-based study. Rheumatology (Oxford) 2013;52:68-75.

5. Trementino L, Arnaldi G, Appolloni G, et al. Coagulopathy in Cushing's syndrome. Neuroendocrinology 2010;92(Suppl 1):55-59. 